\title{
Molecular Characterization of Fluoroquinolone-Resistant Bartonella bacilliformis
}

\author{
Giovanna Mendoza-Mujica ${ }^{1, *}$, Diana Flores-León ${ }^{1}$ and Joaquim Ruiz ${ }^{2, *(D)}$ \\ 1 Laboratorio de Metaxénicas Bacterianas, Centro Nacional de Salud Pública, Instituto Nacional de Salud, \\ Lima 15072, Peru; diacaro_sun@hotmail.com \\ 2 Laboratorio de Microbiología Molecular y Genómica Bacteriana, Universidad Científica del Sur, \\ Lima 15067, Peru \\ * Correspondence: gmm2407@gmail.com (G.M.-M.); joruiz.trabajo@gmail.com (J.R.)
}

check for updates

Citation: Mendoza-Mujica, G.;

Flores-León, D.; Ruiz, J. Molecular Characterization of FluoroquinoloneResistant Bartonella bacilliformis.

Pathogens 2021, 10, 876. https://

doi.org/10.3390/pathogens10070876

Academic Editor: Edward

B. Breitschwerdt

Received: 2 June 2021

Accepted: 7 July 2021

Published: 10 July 2021

Publisher's Note: MDPI stays neutral with regard to jurisdictional claims in published maps and institutional affiliations.

Copyright: (c) 2021 by the authors. Licensee MDPI, Basel, Switzerland. This article is an open access article distributed under the terms and conditions of the Creative Commons Attribution (CC BY) license (https:// creativecommons.org/licenses/by/ $4.0 /)$.

\begin{abstract}
The presence of amino acid changes in GyrA, GyrB, ParC, ParE, and in a proposed chromosomal chloramphenicol acetyl transferase (CAT), as well as mutations at 23S $r R N A$, were established by PCR and sequencing in 38 B. bacilliformis clinical isolates from four different areas in Peru. Eighteen out of 24 (75\%) isolates showing ciprofloxacin resistance for both disk-diffusion and e-test presented amino acid substitutions in GyrA $\left(\mathrm{G}_{89} \mathrm{C}\right.$, six isolates, $\mathrm{A}_{91} \mathrm{~V}, 1$ isolate $) \mathrm{GyrB}\left(\mathrm{S}_{474} \mathrm{~F}\right.$, 10 isolates) or both (GyrA $D_{95} \mathrm{~N}$ and $\mathrm{GyrB} \mathrm{S}_{474} \mathrm{~F}$, one isolate). Two out of 14 susceptible isolates presented amino acid substitutions at $\mathrm{GyrB}\left(\mathrm{S}_{474} \mathrm{~F}\right)$ or a double substitution GyrA $\mathrm{D}_{95} \mathrm{~N}$ and GyrB $\mathrm{S}_{474} \mathrm{~F}$. Of note, ciprofloxacin-resistant isolates were recovered in the four areas studied. No amino acid change was observed at ParC or ParE. Only one isolate showed chloramphenicol resistance, but no alteration was present in either $23 S$ rRNA or CAT. B. bacilliformis resistant to quinolones are extended throughout Peru, with amino acid substitutions at GyrA or GyrB as the main, albeit not exclusive, cause. B. bacilliformis seems to have an apparent facility to develop mutations on GyrB outside the classical positions 91, 95 of GyrA and 85, 88 of ParC.
\end{abstract}

Keywords: Carrion's disease; Bartonella bacilliformis; antibiotic-resistance; GyrA; GyrB; ciprofloxacin; chloramphenicol

\section{Introduction}

Bartonella bacilliformis is the etiological agent of Carrion's disease, which is a biphasic illness, accounting for an acute, the so-called "Oroya fever", and a chronic phase, namely "Peruvian Wart" [1]. Furthermore, the presence of apparent healthy asymptomatic carriers is frequent in endemic areas [2,3]. Up to 14 different multi-locus sequence typing (MLST) patterns have been described in B. bacilliformis [4], with the presence of two subspecies being proposed [5]. Thus, it has been proposed that isolates belonging to sequence type (STs) 1 to 7, 9 to 11 and 13 and 14 be classified within subsp. 1, with the strain KC583 being the representative strain [4,5] and STs 8 and 12 be classified within subsp. 2, with strain Ver097 as the representative strain [4,5]. Of note, Loparev et al. proposed that $B$. bacilliformis subsp. 2 might be another species closely related to B. bacilliformis [6]. While the species or subspecies status of B. bacilliformis belonging to STs 8 and 12 remains to be firmly established, the subdivision subsp. 1/subsp. 2 is followed in the text in order to classify the results obtained.

The disease is restricted to regions in the Peruvian and Ecuadorian Andes [1], with the chronic phase also being reported in a coastal area of Ecuador [1,7]. These cases are probably associated with a related Bartonella sp., as the only molecular report highlights $96.5 \%$ of identity at $16 S r R N A$, but the DNA sequence is not recorded in GenBank [7]. Additionally, the disease was suddenly introduced in Southern Colombia in the first half of the last century, but no confirmed report has been found in the literature for more than 20 years [1]. 
Although Carrion's disease is largely neglected and not on international research agendas [8], in the absence or delay of antibiotic treatment the acute phase of the disease is a deadly infection [9]. Thus, in the pre-antibiotic era severe outbreaks, such as the Central Railway outbreak (1870-1871) and the Southern Colombia outbreak (1936-1946) have been described and accounted for $\sim 7000$ and $\sim 6000$ deaths, respectively [1,10]. At present, severe cases arriving to hospitals have $\sim 10 \%$ of lethality, irrespective of antibiotic treatment [1]. Death is related to extreme severe anemia resulting from red blood cell lysis and transient immunosuppression $[1,11]$ which favors concomitant opportunistic infections such as bacteremic Salmonella sp. infections, or the reactivation of latent infections such as histoplasmosis or toxoplasmosis, among others [12].

$B$. bacilliformis infections are treated with a variety of antibiotics based on both the illness phase and patient characteristics such as age or gravidness [1]. Among these antibiotics, ciprofloxacin and chloramphenicol have played a key role as the treatment of choice for acute phase presentation [1].

Nevertheless, despite the need for antimicrobial therapy and the extended use of the above-mentioned antimicrobial agents, the geographical restriction of the disease to lowresource rural areas has resulted in a lack of studies aimed at evaluating its susceptibility to antibiotics. Thus, while it is usually considered that the current levels of antimicrobial resistance of $B$. bacilliformis are negligible, both clinical and microbiological failures have been reported [12,13]. In fact, the number of reports analyzing the antibiotic susceptibility of clinical isolates is extremely scarce and mostly limited to a few microorganisms [14-16]. Of these, the largest B. bacilliformis series, including 100 clinical isolates, focused on the analysis of chloramphenicol and ciprofloxacin resistance levels and reported the presence of $1 \%$ and $26 \%$ of chloramphenicol and ciprofloxacin resistance, respectively [14].

Similarly, there are almost no data on the presence of possible or potential mechanisms of antibiotic resistance for recent field-recovered $B$. bacilliformis. To the best of our knowledge, the gyr $A$ and parC quinolone resistance determining regions (QRDR) have been analyzed in a few clinical isolates, but no mutation was detected [15]. In fact, current knowledge about the mechanisms of antimicrobial resistance of B. bacilliformis is based on the analysis of mutants or collection strains obtained in vitro and mainly collected in the field more than 40 years ago [16-20]. Nevertheless, these studies have shown the feasibility of the development of antibiotic resistance to common B. bacilliformis treatments, and the possibility of this resistance becoming stable or transient [19]. This finding might underlie the presence of clinical failures, but especially the largely described microbiological failures [1].

In this scenario, this study aimed to determine the most frequent mechanisms of quinolone and chloramphenicol resistance in a large series of B. bacilliformis clinical isolates representative of different endemic areas of Peru.

\section{Results}

\subsection{Classification of the Isolates}

The results showed that the QRDR sequences belonging to 27 (71.1\%) isolates were identical (except for punctual mutations in the target genes analyzed, which are described in the next section) to those of Cond044 (classified within ST2) or Peru18 (classified within ST5), and were thereby classified as B. bacilliformis subsp. 1. Meanwhile, 10 isolates presented QRDR sequences (except that of ParE, which was identical to that of subsp. 1 in all cases) concordant to those of the strain Ver097 (classified within ST12), and were then classified as B. bacilliformis subsp. 2. In addition, 1 isolate presented GyrA, GyrB and ParE identical to those of subsp. 1 and ParC identical to that of subsp. 2 (Table 1), while 32 out of $38(84.2 \%)$ isolates showed a proposed chromosomal encoded chloramphenicol acetyl transferase (CAT) concordant with B. bacilliformis subsp. 1, which was identical to that of B. bacilliformis subsp. 2 in the remaining 6 isolates (Table 1). No differences were detected with the sequenced region of the $23 S$ rRNA as it was identical in all the B. bacilliformis genomes. Overall, 12 out of 38 (31.6\%) isolates presented new sequence combinations of the studied targets. 
Table 1. Identity of the isolates with Bartonella bacilliformis genomes present in GenBank.

\begin{tabular}{ccccccc}
\hline & & \multicolumn{3}{c}{ subsp. 1 $^{\mathbf{1}}$} & \multicolumn{2}{c}{ subsp. 2 } \\
\cline { 3 - 7 } & & Cond044 $^{\mathbf{2}}$ & Peru18 $^{\mathbf{3}}$ & Other $^{\mathbf{4}}$ & Ver097 $^{\text {Other }^{\mathbf{4}}}$ \\
\hline Ancash & Center & 1 & 1 & $1^{5}$ & 6 & $4^{6}$ \\
Cajamarca & North & 1 & 3 & & & \\
Cusco & South & & 19 & $1^{7}$ & & \\
Piura & North & & 1 & & &
\end{tabular}

Genomes grouped by amino acid identity of the sequenced regions. Of these regions few punctual amino acid differences may be present. ${ }^{1}$ While differences between the sequences of the genomes grouped together as KC583 and that of Ver097 are well established [4-6], subdivision of subspecies remains to be confirmed. Of note, all isolates classified within subsp. 2 presented ParE coincident with subsp. $1 .{ }^{2}$ The sequenced regions were also identical to those of CAR600-02, Hosp800-02 and VAB9028. ${ }^{3}$ The sequenced regions were also identical to those of CUSCO5 and USM-LMMB-07. ${ }^{4}$ Isolates presenting several sequences identical to those recorded for B. bacilliformis subsp. 1 and others identical to those of B. bacilliformis subsp. 2 . The presence under subsp. 1 or subsp. 2 categories was based on the greater number of concordances. ${ }^{5}$ GyrA, ParE cand CmlA coincident with Cond044, GyrB and ParC coincident with Ver097. ${ }^{6}$ GyrA, GyrB, ParC and ParE concordant with Ver097 and CAT with subsp. 1. ${ }^{7}$ GyrA coincident with Peru18 and GyrB coincident with Cond044. The remaining proteins were identical in both genomes.

\subsection{Mechanisms of Resistance to Quinolones and Chloramphenicol}

Of the 38 isolates, $24(63.2 \%)$ were classified as resistant to ciprofloxacin, with all showing full concordance between disk halo and minimum inhibitory concentration (MIC) (halo diameters between 6 and $10 \mathrm{~mm}$ ). Of the 24 ciprofloxacin-resistant isolates, $18(75.0 \%)$ presented at least one amino acid change at GyrA and/or GyrB. Regarding ciprofloxacin susceptible isolates, only 2 out of $14(14.2 \%)$ presented target mutations at QRDR regions. One isolate showing the highest MIC levels among the ciprofloxacin susceptible isolates presented GyrA $\left(\mathrm{D}_{95} \mathrm{~N}\right)$ and $\mathrm{GyrB}\left(\mathrm{S}_{474} \mathrm{~F}\right)$, and another showed an amino acid substitution $\mathrm{S}_{474} \mathrm{~F}$ at GyrB (Table 2; Figure 1).

Table 2. Amino acid changes at GyrA and GyrB.

\begin{tabular}{|c|c|c|c|c|c|c|c|c|}
\hline & & & & GyrA & & GyrB & & \\
\hline & $\mathbf{N}$ & MIC & 89 & 91 & 95 & 474 & Identity ${ }^{1}$ & Region \\
\hline \multirow[t]{22}{*}{ wt } & - & - & G & A & $\mathrm{D}$ & $\mathrm{S}$ & & \\
\hline & 1 & 0.047 & - & - & - & - & V97 & A \\
\hline & 4 & 0.064 & - & - & - & - & V97 (3), M1 (1) & A \\
\hline & 2 & 0.094 & - & - & - & - & V97 (1), P18 (1) & $\mathrm{A}, \mathrm{Cu}$ \\
\hline & 1 & 0.094 & - & - & - & $\mathrm{F}$ & P18 & $\mathrm{Cu}$ \\
\hline & 1 & 0.125 & - & - & - & - & C044 & $\mathrm{Cj}$ \\
\hline & 2 & 0.19 & - & - & - & - & V97 & A \\
\hline & 2 & 0.25 & - & - & - & - & V97 (1), C044 (1) & A, $P$ \\
\hline & 1 & 0.38 & - & - & $\mathrm{N}$ & $\mathrm{F}$ & P18 & $\mathrm{Cj}$ \\
\hline & 2 & 1 & $\mathrm{C}$ & - & - & - & P18 & $\mathrm{Cu}$ \\
\hline & 2 & 1 & - & - & - & $\mathrm{F}$ & P18 & $\mathrm{Cu}$ \\
\hline & 1 & 2 & C & - & - & - & P18 & A \\
\hline & 4 & 2 & - & - & - & $\mathrm{F}$ & P18 & $\mathrm{Cu}$ \\
\hline & 1 & 2 & - & - & $\mathrm{N}$ & $\mathrm{F}$ & P18 & $\mathrm{Cu}$ \\
\hline & 1 & 3 & - & - & - & $\mathrm{F}$ & P18 & $\mathrm{Cu}$ \\
\hline & 1 & 4 & - & - & - & $\mathrm{F}$ & P18 & $\mathrm{Cu}$ \\
\hline & 1 & 16 & - & - & - & - & V97 & A \\
\hline & 1 & 32 & - & $\mathrm{V}$ & - & - & P18 & $\mathrm{Cu}$ \\
\hline & 1 & 32 & - & - & - & $\mathrm{F}$ & P18 & $\mathrm{Cu}$ \\
\hline & 5 & $>32$ & - & - & - & - & $\begin{array}{l}\text { V97 (1), C044 (1), } \\
\text { P18 (2). M2 (1) }\end{array}$ & $\mathrm{A}, \mathrm{Cj}, \mathrm{Cu}$ \\
\hline & 3 & $>32$ & $\mathrm{C}$ & - & - & - & P18 & $\mathrm{Cu}$ \\
\hline & 1 & $>32$ & - & - & - & $\mathrm{F}$ & P18 & $\mathrm{Cu}$ \\
\hline
\end{tabular}

A: Ancash, Cj: Cajamarca; Cu: Cusco; P: Piura. V97: Ver097; P18: Peru18: C044: Cond044; M1: Mixed characteristics Cond044 (GyrA)/Ver097 (GyrB); M2: Mixed characteristics Peru18 (GyrA)/Cond044 (GyrB). Both M1 and M2 classified as subsp. 1 in Table 1.

${ }^{1}$ Identity of the sequenced GyrA and GyrB with those belonging to genomes present in GenBank. 


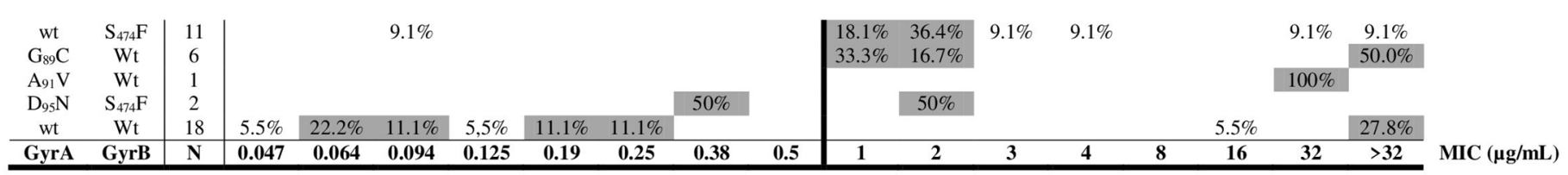

Figure 1. Distribution of minimal inhibitory concentrations (MIC). wt: wild type. Any MIC category with $\geq 10 \%$ of the isolates is highlighted in dark grey.

Overall, the most frequent amino acid change was found at position 474 of GyrB with 13 isolates showing the change $\mathrm{S}_{474} \mathrm{~F}$. Of these, two also carried the GyrA amino acid change $\mathrm{D}_{95} \mathrm{~N}$. The remaining amino acid alterations were located in GyrA with the amino acid change $\mathrm{G}_{89} \mathrm{C}$ and $\mathrm{A}_{91} \mathrm{~V}$ present in six and one isolates, respectively (Table 2). No amino acid change was observed in ParC and ParE.

Despite detecting isolates with a MIC of ciprofloxacin of 16 and $>32 \mu \mathrm{g} / \mathrm{mL}$, none of the isolates showing identity with Ver097 or Cond044 presented target alterations. On the other hand, the presence of ciprofloxacin-resistant isolates was observed in all the geographical areas analyzed, except for Piura, from which the only isolate analyzed presented a MIC of $0.25 \mu \mathrm{g} / \mathrm{mL}$.

Only 1 out of 38 isolates (2.6\%) (isolate Ancash-3) showed resistance to chlorampheni$\operatorname{col}(\mathrm{MIC}=1 \mu \mathrm{g} / \mathrm{mL}$; disk halo $=10 \mathrm{~mm})$. No point mutations at $23 \mathrm{~S} r R N A$ or amino acid differences in the cat gene other than those differentiating B. bacilliformis subsp. 1 and subsp. 2 were observed.

\section{Discussion}

B. bacilliformis is a microorganism that is difficult to grow and mainly affects rural Andean areas, with non-adequate equipment to culture or perform molecular analysis to identify or characterize this microorganism. Furthermore, endemic areas are mostly off touristic routes, resulting in a lack of visibility and leaving Carrion's disease under the radar of research fundraisers [8]. The result is the presence of deep gaps in knowledge about this illness, including information regarding its genetic diversity and the levels of antimicrobial resistance of clinical isolates of this microorganism. Thus, in addition to the presence of a new variant of subsp. 2 carrying a ParE amino acid sequence identical to that of subsp. 1, this finding is highlighted by the presence of another $15.8 \%$ of isolates possessing non-described sequence combinations of the targets analyzed, including other isolates presenting mixed characteristics of subsp. 1 and subsp. 2 . To date, only 16 isolates have been fully sequenced (https://www.ncbi.nlm.nih.gov/genome/browse/\#!/prokaryotes/ bartonella\%20bacilliformis, accessed on 9 July 2021), with data about MLST patterns being limited to 64 isolates (https:/ / pubmlst.org/organisms/bartonella-bacilliformis, accessed on 9 July 2021). The present data demonstrate the need to characterize a high number of $B$. bacilliformis clinical isolates in order to dispose of a correct scenario of the genetic diversity of this microorganism.

The difficulty and the time required to culture B. bacilliformis from clinical samples preclude the analysis of MIC levels for guiding antibiotic treatments. Thus, in addition to national guidelines, treatment of Carrion's disease is mainly based on personal experience [1]. Nevertheless, the presence of therapeutic and microbiological failures strongly suggests the presence of $B$. bacilliformis isolates possessing mechanisms of resistance to the antimicrobial agents administered. In this sense, in vitro studies have led to the obtaining of mutants exhibiting high levels of resistance to different antimicrobial agents, including quinolones or chloramphenicol, among others $[17,19,20]$.

In contrast to what is largely described in Gram-negative microorganisms [21], the relevance of GyrB in the increase of resistance levels to quinolones seems to be at least as relevant as that of GyrA. This finding might be associated with the presence of a wildtype alanine in both positions 91 and 85 of GyrA and ParC, respectively [18]. The presence of 
alanine in the equivalent position of other microorganisms (for instance, in Escherichia coli positions 83 of GyrA and 80 of ParC) has been related to the development of low levels of ciprofloxacin resistance [21,22], and it is considered the reason underlying the constitutive resistance to nalidixic acid presented by Bartonella spp. $[18,23]$. Thus, the presence of an additional amino acid substitution in another hot-spot would probably be more beneficial in terms of survival in the presence of ciprofloxacin, than by the modification of either of these 2 amino acids. In this sense it should be considered that the effect of mutations in the QRDR is additive [21]. While to our knowledge, this is the first description of an amino acid substitution $\mathrm{S}_{474} \mathrm{~F}$ in B. bacilliformis, in other microorganisms, such as E. coli, Legionella pneumophila, Salmonella enterica, Pseudomonas aeruginosa or Proteus mirabilis, the presence of amino acid substitutions (including from $S$ to $F$ ) in the equivalent position has been largely involved in the development of resistance to quinolones [24-28]. Twelve of the 13 isolates presenting this alteration (10 alone, and two concomitantly with the GyrA substitution $\mathrm{D}_{95} \mathrm{~N}$ ) were recovered from the same geographical region (Cusco) in 2008-2009, with the remaining isolate being from Cajamarca, and in all cases the sequenced regions were concordant with those of the Peru 18 strain. In this scenario, the presence of a successful clone disseminated in the Cusco department cannot be ruled out.

Regarding amino acid substitutions in GyrA, and in accordance with the possible benefit of mutations outside positions Ala ${ }_{91}(\mathrm{GyrA})$ and $\mathrm{Ala}_{95}$ (ParC), only one out of nine isolates with amino acid substitutions at GyrA presented the substitution at position 91 $\left(\mathrm{A}_{91} \mathrm{~V}\right)$. The remaining eight isolates presented amino acid substitutions at positions 89 $\left(\mathrm{G}_{89} \mathrm{C}\right)$ or $95\left(\mathrm{D}_{95} \mathrm{~N}\right)$, and as mentioned above, the latter was concomitant with $\mathrm{S}_{474} \mathrm{~F}$ at $\mathrm{GyrB}$. Substitutions at positions 91 and 95 of GyrA (or equivalent position in other microorganisms) rank among the most frequently described in quinolone-resistant microorganisms and have been previously described in in vitro mutants of $B$. bacilliformis [17,19-21]. An amino acid substitution at $\mathrm{G}_{89}$ is a less frequent alteration that has previously been described as a cause of quinolone resistance in different microorganisms such as E. coli, L. pneumophila, $S$. enterica or Mycobacterium leprae, among others [24,29-31]. Interestingly, it has been reported that amino acid substitutions at this position often result in lower levels of resistance than those affecting positions equivalent to GyrA 91 of B. bacilliformis [30], with a low level of protection of the catalytic activity of GyrA in the presence of ciprofloxacin [32]. This finding again supports the greater facility of $B$. bacilliformis to develop mutations outside classical quinolone-resistant hot-spots.

In addition, six isolates showing resistance to ciprofloxacin did not possess any substitution at GyrA, GyrB, ParC or ParE, with five presenting MICs $>32 \mu \mathrm{g} / \mathrm{mL}$. In this sense, Gomes et al. [19] observed that after five passages in the absence of ciprofloxacin, the MIC levels of a previously obtained highly resistant mutant (MICs $>32 \mu \mathrm{g} / \mathrm{mL}$ ) decreased to $1.5 \mu \mathrm{g} / \mathrm{mL}$, while maintaining the GyrB substitution $\mathrm{E}_{475} \mathrm{~K}$. These findings highlight the presence of other mechanisms involved in the development of high levels of ciprofloxacin resistance, such as, for instance, efflux pumps (inhibitable or not by substances such as artesunate or Phe-Arg- $\beta$-Naphtylamyde), permeability alterations, or others. Of note, to date no transferable mechanism of quinolone resistance has been described in B. bacilliformis [18]. Similarly, the high variety of the ciprofloxacin MICs observed in isolates presenting the same amino acid substitution might also be related to the presence of different levels of permeability or the activity of efflux pumps. In this sense, while mutations at the QRDR impairs quinolone activity, resulting in the most frequent mechanisms of quinolone resistance [21], the presence of quinolone-susceptible (including ancient quinolones, such as nalidixic acid) microorganisms presenting quinolone-target mutations has occasionally been described and attributed to an unusual high uptake of quinolones related to outer membrane alterations leading to increased permeability and/or due to efflux pump malfunction [33].

Only one isolate showed resistance to chloramphenicol ( $\mathrm{MIC}=1 \mu \mathrm{g} / \mathrm{mL}$ ). This finding agrees with the difficulty in obtaining chloramphenicol-resistant mutants in vitro [19], which might thereby be extrapolated to clinical isolates. Interestingly, this isolate did 
not present any mutation at $23 S$ rRNA or an amino acid substitution on CAT, with this MIC remaining unexplained. A B. bacilliformis mutant with a MIC of chloramphenicol of $4 \mu \mathrm{g} / \mathrm{mL}$ has previously been obtained and, similar to the present isolate, no alteration at $23 S$ rRNA was observed (the cat gene was not analyzed) [19]. Nevertheless, when the MIC was established in the presence of Phe-Arg- $\beta$-Naphtylamyde, it decreased to $1 \mu \mathrm{g} / \mathrm{mL}$, while in the presence of artesunate it decreased to $1.5 \mu \mathrm{g} / \mathrm{mL}$ [19]. Furthermore, after 5 passages in the absence of antibiotic, the MIC of chloramphenicol decreased to $0.125 \mu \mathrm{g} / \mathrm{mL}$, highlighting the instability of the selected mechanism of resistance [19]. A similar presence of overexpressed efflux pump might underlie, at least in part, the MIC levels of the present isolate.

While CAT is recorded in GenBank as a chloramphenicol acetyl transferase, the present data suggest that, at least in its wildtype stage, CAT plays no role or only has a spurious implication in the development of clinical levels of chloramphenicol resistance.

The present data highlight that the absence of amino acid substitutions in quinolone targets cannot be assumed as synonymous with susceptibility to quinolones in $B$. bacilliformis clinical isolates. Nevertheless, $75 \%$ of the ciprofloxacin-resistant isolates showed at least one amino acid substitution at GyrA or GyrB. This scenario opens the possibility of directly analyzing the presence of altered quinolone-targets (or targets of other antibacterial agents) from blood/tissue samples to better guide patient treatment, although it would likely be limited to reference centers. In this sense, direct amplification of different genes has been performed directly from blood samples [34], and the utility of dried blood spots (useful for the transfer of blood samples from endemic areas to reference centers) for the detection of $B$. bacilliformis has been validated for both conventional and quantitative PCR $[35,36]$.

The main limitation of the present study is the lack of clinical data on the treatments and outcomes of patients, which might help to better understand the significance and relevance of the mechanisms of resistance detected.

In summary, the presence of $B$. bacilliformis resistant to fluoroquinolones is extended throughout Peru and is mainly related to the presence of point mutations in GyrA or GyrB. Analysis of a large number of isolates, expansion of the studies to B. bacilliformis isolated in other areas, and the introduction of the study of other antibiotic targets should be the next steps to obtain a more complete scenario of the levels and mechanisms of resistance presented by B. bacilliformis.

\section{Materials and Methods}

\subsection{Microorganisms}

Thirty-eight $B$. bacilliformis isolates collected from blood samples of Carrion's disease patients (all presenting the acute phase of infection) from different regions of Peru (Southern Peru: Cusco; Northern Peru; Cajamarca, Piura; Central Peru: Ancash) between 2005 and 2011 were included in the study (Figure 2).

The microorganisms were recovered from frozen stocks cultured for 6-8 days in biphasic media (solid phase: Columbia agar plus 10\% sheep blood; liquid phase: RPMI 1640 plus L-glutamine and $\mathrm{NaHCO}_{3}$ ) [14]. Thereafter, $500 \mu \mathrm{L}$ of liquid phase were subcultured in Columbia agar plus 10\% sheep blood for 4-5 days [14]. All cultures were performed in microaerophilic conditions at $28{ }^{\circ} \mathrm{C}$ [14]. Before molecular analysis, the isolates were confirmed as Bartonella spp. by amplification of the ialB gene, following previously established procedures [37]. 


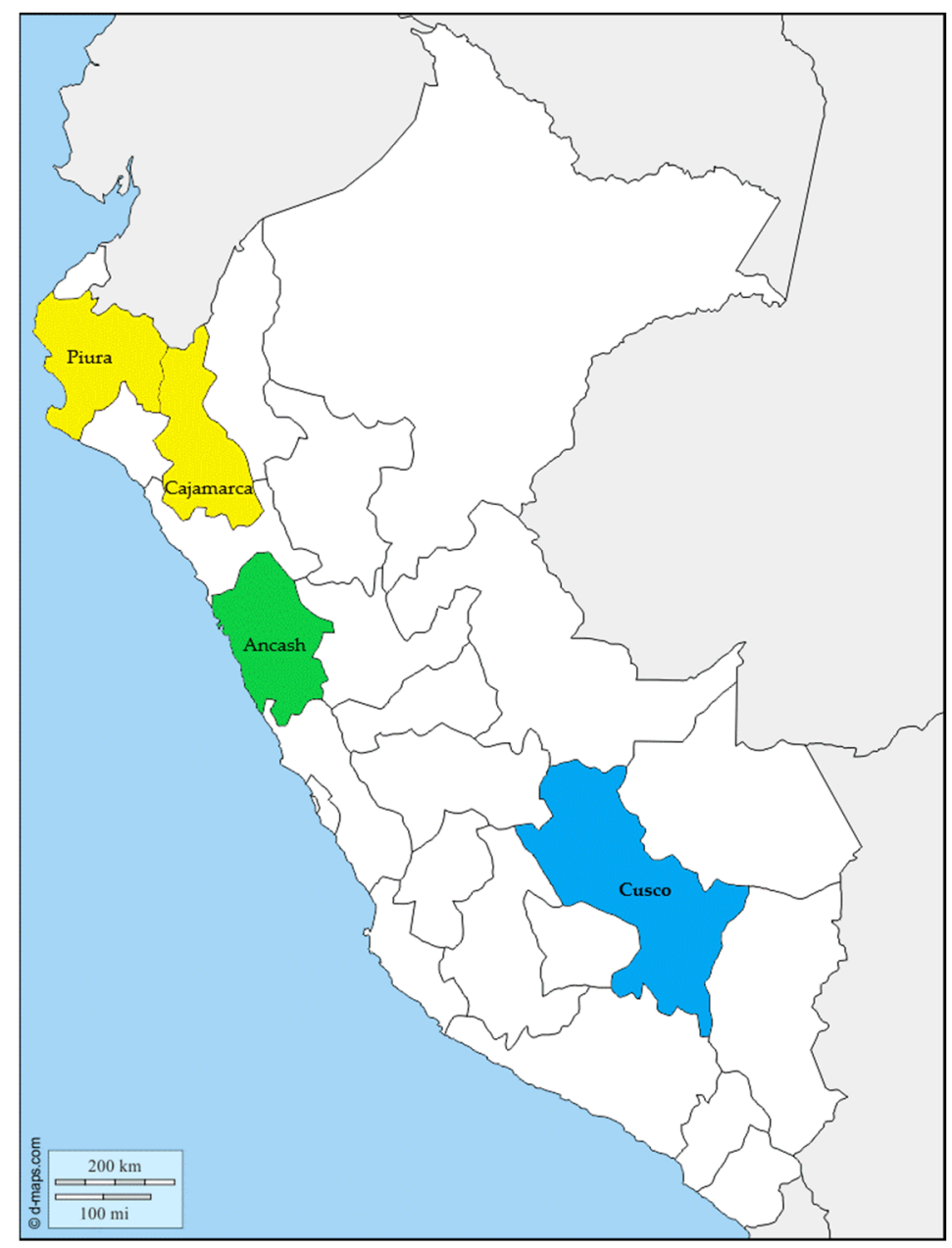

Figure 2. Map of Peru. The colored areas show the areas where the isolates studied originated. In yellow Piura and Cajamarca (Northern Peru); in green Ancash (Central Peru); in blue Cusco (Southern Peru). Map modify from https:/ /d-maps.com/carte.php?num_car=4764\&lang=es (accessed on 9 July 2021), (c) 2007-2021 https:/ / d-maps.com/, accessed on 9 July 2021.

\subsection{Antibiotic Susceptibility}

Information of susceptibility levels to chloramphenicol and ciprofloxacin have been reported previously [14]. In all cases susceptibility levels were reconfirmed by both disk diffusion and e-test as described previously [14].

In the absence of established breakpoints, the resistance breakpoint criteria for both ciprofloxacin and chloramphenicol were a MIC $\geq 1 \mu \mathrm{g} / \mathrm{mL}$ and/or disk halo $\leq 20 \mathrm{~mm}$ [14].

\subsection{DNA Extraction}

B. bacilliformis were recovered from plates, resuspended in $1 \mathrm{~mL}$ of molecular grade water, and processed using the PureLinkTM Genomic DNA Kit (Invitrogen ${ }^{\circledR}$, Waltham, MA, USA) following the manufacturer's instructions.

\subsection{Molecular Analysis of Antibiotic Targets}

The presence of mutations at $23 S r R N A, g y r A, g y r B$, parC and parE was determined by PCR and sequencing (see below). In addition, the locus WP_005767400 (which is proposed to encode a chloramphenicol acetyl transferase, referred to in the text as CAT/cat), was also amplified. All targets were amplified using the primers and conditions reported in Table 3. The amplified products were purified using the QIAquick ${ }^{\circledR}$ PCR Purification (QUIAGEN, Carlsbad, CA, USA), and the purified product was quantified. 
Table 3. Primers used in the study.

\begin{tabular}{|c|c|c|c|c|c|c|}
\hline \multirow[b]{2}{*}{ Primer } & \multirow[b]{2}{*}{ Sequence $5^{\prime}-3^{\prime}$} & \multirow[b]{2}{*}{ Target } & \multicolumn{4}{|c|}{ Annealing } \\
\hline & & & Size $^{1}$ & ${ }^{\circ} \mathrm{C}$ & Sec & Ref \\
\hline gyrA-F & GACCGATCTTACTCGACTACC & \multirow{2}{*}{ gyrA } & \multirow{2}{*}{701} & \multirow{2}{*}{57} & \multirow{2}{*}{30} & \multirow{2}{*}{ [38] } \\
\hline gyrA-R & ATAAGCAGAACGGACACCAGA & & & & & \\
\hline gyrB-F & ATGAAGGACTTTCAGCATGGC & \multirow{2}{*}{ gyrB } & \multirow{2}{*}{766} & \multirow{2}{*}{59} & \multirow{2}{*}{30} & \multirow[b]{2}{*}{ TS } \\
\hline gyrB-R & ATTGAAAGCACCAGCGATTG & & & & & \\
\hline parC-F & AGAACTACGTTCTGCTTTGC & \multirow{2}{*}{ parC } & \multirow{2}{*}{621} & \multirow{2}{*}{55} & \multirow[b]{2}{*}{30} & \multirow[b]{2}{*}{ TS } \\
\hline parC-R & AACCAAAATGCCACCTGTTG & & & & & \\
\hline parE-F & AATAGGAAATAAGCGTGCCTCG & \multirow{2}{*}{ parE } & \multirow{2}{*}{750} & \multirow{2}{*}{59} & \multirow{2}{*}{30} & \multirow{2}{*}{ TS } \\
\hline parE-R & TCTTTATGAGAATCGTCGCGT & & & & & \\
\hline $23 S$ rRNA-F & CAAGCATTGAATTGAAGCCCC & \multirow{2}{*}{$23 S r R N A$} & \multirow[b]{2}{*}{1020} & \multirow{2}{*}{58} & \multirow[b]{2}{*}{30} & \multirow[b]{2}{*}{ TS } \\
\hline $23 S$ rRNA-R & AATGAGAACGATCAAGCCAATC & & & & & \\
\hline CAT-F & ATTGAGAGTATGGGAATGGTTTT & \multirow{2}{*}{ WP_005767400 ${ }^{2}$} & \multirow{2}{*}{796} & \multirow{2}{*}{54} & \multirow{2}{*}{30} & \multirow{2}{*}{ TS } \\
\hline CAT-R & CGTGTTCTCGACAATTTTGTTA & & & & & \\
\hline ialB-F & ATGAAAAAAATATTAAATTTAATTTG & \multirow{2}{*}{ ialB } & \multirow{2}{*}{558} & \multirow{2}{*}{58} & \multirow{2}{*}{60} & [37] \\
\hline ialB-R & TTTTTGCAAAGAAGTTAAACGCTTAAG & & & & & [3/] \\
\hline
\end{tabular}

All the PCR programs have 30 cycles. In all cases a final extension of $72{ }^{\circ} \mathrm{C}$ for $7 \mathrm{~min}$ was added at the end of the program. TS: This study. ${ }^{1}$ Established in all cases in the genome of the strain B. bacilliformis KC583 (GenBank access: CP000524). ${ }^{2}$ RefSeq (representative of B. bacilliformis subsp. 1) present in GenBank, recorded as "antibiotic acetyltransferase". In the equivalent RefSeq WP_041849707 (B. bacilliformis subsp. 2), it is recorded as "chloramphenicol acetyltransferase".

\subsection{DNA Sequencing}

The DNA sequencing was carried out in an ABI 3500xL Genetic Analyzer (Applied Biosystems, Foster City, CA, USA) using the Big Dye ${ }^{\circledR}$ Terminator v3.1 Cycle Sequencing Kit (Applied Biosystems). All the amplified products were sequenced in both directions. The sequences were analyzed accordingly to B. bacilliformis genomes present in GenBank. The software packages BioEdit 7.0 [39] and MEGA 5.2 [40] were used to analyze and align the DNA sequences.

Author Contributions: Conceptualization, G.M.-M., and D.F.-L.; methodology, G.M.-M. and D.F.-L.; formal analysis, G.M.-M., D.F.-L. and J.R.; investigation, G.M.-M. and D.F.-L.; resources, G.M.-M.; writing-original draft preparation, J.R.; writing-review and editing, G.M.-M., D.F.-L. and J.R.; visualization, J.R. All authors have read and agreed to the published version of the manuscript.

Funding: The study “Caracterización molecular de cepas de Bartonella bacilliformis resistentes a los antimicrobianos, procedentes de localidades endémicas del Perú" was supported by the Instituto Nacional de Salud.

Institutional Review Board Statement: Not applicable.

Informed Consent Statement: Not applicable.

Data Availability Statement: The data presented in this study are available in [Resistencia antimicrobiana de cepas de Bartonella bacilliformis procedentes de regiones endémicas de la enfermedad de Carrión en el Perú] as well within the present manuscript.

Acknowledgments: We thank Abraham Espinoza for technical support and Donna Pringle for language correction.

Conflicts of Interest: The authors declare no conflict of interest. The funders had no role in the design of the study; in the collection, analyses, or interpretation of data; in the writing of the manuscript, or in the decision to publish the results.

\section{References}

1. Gomes:, C.; Ruiz, J. Carrion's disease. The sound of silence. Clin. Microb. Rev. 2018, 31, e00056-17. [CrossRef]

2. Chamberlin, J.; Laughlin, L.W.; Romero, S.; Solórzano, N.; Gordon, S.; Andre, R.G.; Pachas, P.; Friedman, H.; Ponce, C.; Watts, D. Epidemiology of endemic Bartonella bacilliformis: A prospective cohort study in a Peruvian mountain valley community. J. Infect. Dis. 2002, 186, 983-990. [CrossRef] [PubMed] 
3. Gomes, C.; Palma, N.; Pons, M.J.; Magallón-Tejada, A.; Sandoval, I.; Tinco-Valdez, C.; Gutarra, C.; del Valle-Mendoza, J.; Ruiz, J.; Matsuoka, M. Succinyl-CoA synthetase: New antigen candidate of Bartonella bacilliformis. PLoS Negl. Trop. Dis. 2016, 10, e0004989. [CrossRef] [PubMed]

4. Ruiz, J.; Pons, M.J. Revisiting Bartonella bacilliformis MLST. Infect. Genet. Evol. 2018, 63, 231-235. [CrossRef] [PubMed]

5. Paul, S.; Minnick, M.F.; Chattopadhyay, S. Mutation-driven divergence and convergence indicate adaptive evolution of the intracellular human-restricted pathogen, Bartonella bacilliformis. PLoS Negl. Trop. Dis. 2016, 10, e0004712. [CrossRef] [PubMed]

6. Loparev, V.N.; Dasch, G.A.; Knipe, K.M.; Rowe, L.A.; Lydy, S.L. Optical mapping and genome sequences of isolates of Bartonella bacilliformis. In Proceedings of the Program and Abstracts Book of International Conference on Emerging Infectious Diseases, Atlanta, GA, USA, 24-26 August 2015; Centers for Disease Control and Prevention: Atlanta, GA, USA, 2015; p. 6.

7. Amano, Y.; Rumbea, J.; Knobloch, J.; Olson, J.; Kron, M. Bartonellosis in Ecuador: Serosurvey and current status of cutaneous verrucous disease. Am. J. Trop Med. Hyg. 1997, 57, 174-179. [CrossRef] [PubMed]

8. Gomes, C.; Pons, M.J.; del Valle, M.J.; Ruiz, J. Carrion's disease: An eradicable illness? Infect. Dis Poverty 2016, 5, 105. [CrossRef] [PubMed]

9. $\quad$ Ellis, B.A.; Rotz, L.D.; Leake, J.A.; Samalvides, F.; Bernable, J.; Ventura, G.; Padilla, C.; Villaseca, P.; Beati, L.; Regnery, R.; et al. An outbreak of acute bartonellosis (Oroya fever) in the Urubamba region of Peru, 1998. Am. J. Trop. Med. Hyg. 1999, 61, 344-349. [CrossRef]

10. Patiño-Camargo, L. Fiebre verrucosa del Guaitara en Colombia. Rev. Fac. Med. 1952, 20, 657-705.

11. Ticona, E.; Huaroto, L.; Garcia, Y.; Vargas, L.; Madariaga, M.G. The pathophysiology of the acute phase of human bartonellosis resembles AIDS. Med. Hypotheses 2010, 74, 45-49. [CrossRef]

12. Maguiña, C.; García, P.J.; Gotuzzo, E.; Cordero, L.; Spach, D.H. Bartonellosis (Carrión's disease) in the modern era. Clin. Infect. Dis. 2001, 33, 772-779. [CrossRef]

13. Pachas, P.; Rojas, Y.; Solorzano, N.; Chiroque, J.; Chancafe, J.A.; Canal, E.; Suarez-Ognio, L.; Maguiña, M.; Tarazona, A.; Salazar, J.; et al. Persistence of bacteremia by Bartonella bacilliformis post treatment with cloranfenicol, Ancash, Peru. In Proceedings of the Abstracts of the 55th ASTMH Annual Meeting, Atlanta, GA, USA, 12-16 November 2006; p. 229.

14. Mendoza-Mujica, G.; Flores-León, D. Resistencia antimicrobiana de cepas de Bartonella bacilliformis procedentes de regiones endémicas de la enfermedad de Carrión en el Perú. Rev. Peru. Med. Exp. Salud Publica 2015, 32, 659-666. [CrossRef]

15. Silva-Caso, W.; Pons, M.J.; Tinco, C.; Ruiz, J.; del Valle, J. Antibiotic resistance in Bartonella bacilliformis clinical isolates from an endemic area of Peru. J. Glob. Antimicrob. Resist. 2015, 3, 222-223. [CrossRef]

16. Sobraquès, M.; Maurin, M.; Birtles, R.J.; Raoult, D. In vitro susceptibilities of four Bartonella bacilliformis strains to 30 antibiotic compounds. Antimicrob. Agents Chemother. 1999, 43, 2090-2092. [CrossRef]

17. Biswas, S.; Raoult, D.; Rolain, J.M. Molecular mechanisms of resistance to antibiotics in Bartonella bacilliformis. J. Antimicrob. Chemother. 2007, 59, 1065-1070. [CrossRef] [PubMed]

18. Del Valle, L.J.; Flores, L.; Vargas, M.; de la-Guarda, R.G.; Quispe, R.L.; Ibañez, Z.B.; Alvarado, D.; Ramírez, P.; Ruiz, J. Bartonella bacilliformis, endemic pathogen of the Andean region, is intrinsically resistant to quinolones. Int. J. Infect. Dis. 2010, 14, 506-510. [CrossRef] [PubMed]

19. Gomes, C.; Martínez-Puchol, S.; Ruiz-Roldán, L.; Pons, M.J.; del Valle, J.; Ruiz, J. Development and characterisation of highly antibiotic resistant Bartonella bacilliformis mutants. Sci. Rep. 2016, 6, 33584. [CrossRef] [PubMed]

20. Minnick, M.F.; Wilson, Z.R.; Smitherman, L.S.; Samuels, D.S. gyrA mutations in ciprofloxacin-resistant Bartonella bacilliformis strains obtained in vitro. Antimicrob. Agents Chemother. 2003, 47, 383-386. [CrossRef] [PubMed]

21. Ruiz, J. Mechanisms of resistance to quinolones: Target alterations, decreased accumulation and DNA gyrase protection. J. Antimicrob. Chemother. 2003, 51, 1109-1117. [CrossRef] [PubMed]

22. Vila, J.; Vargas, M.; Ruiz, J.; Corachan, M.; de Anta, M.T.J.; Gascón, J. Quinolone resistance in enterotoxigenic Escherichia coli causing diarrhea in travelers to India in comparison with other geographical areas. Antimicrob. Agents Chemother. 2000, 44, 1731-1733. [CrossRef]

23. Angelakis, E.; Biswas, S.; Taylor, C.; Raoult, D.; Rolain, J.M. Heterogeneity of susceptibility to fluoroquinolones in Bartonella isolates from Australia reveals a natural mutation in gyrA. J. Antimicrob. Chemother. 2008, 61, 1252-1255. [CrossRef] [PubMed]

24. Almahmoud, I.; Kay, E.; Schneider, D.; Maurin, M. Mutational paths towards increased fluoroquinolone resistance in Legionella pneumophila. J. Antimicrob. Chemother. 2009, 64, 284-293. [CrossRef] [PubMed]

25. Bhatnagar, K.; Wong, A. The mutational landscape of quinolone resistance in Escherichia coli. PLoS ONE 2019, 14, e0224650. [CrossRef] [PubMed]

26. Mouneimné, H.; Robert, J.; Jarlier, V.; Cambau, E. Type II topoisomerase mutations in ciprofloxacin-resistant strains of Pseudomonas aeruginosa. Antimicrob. Agents Chemother. 1999, 43, 62-66. [CrossRef] [PubMed]

27. Tanmoy, A.M.; Westeel, E.; De Bruyne, K.; Goris, J.; Rajoharison, A.; Sajib, M.S.I.; van Belkum, A.; Saha, S.K.; Komurian-Pradel, F.; Endtz, H.P. Salmonella enterica serovar Typhi in Bangladesh: Exploration of genomic diversity and antimicrobial resistance. $m B i o$ 2018, 9, e02112-18. [CrossRef] [PubMed]

28. Weigel, L.M.; Anderson, G.J.; Tenover, F.C. DNA gyrase and topoisomerase IV mutations associated with fluoroquinolone resistance in Proteus mirabilis. Antimicrob. Agents Chemother. 2002, 46, 2582-2587. [CrossRef] [PubMed]

29. Matrat, S.; Cambau, E.; Jarlier, V.; Aubry, A. Are all the DNA gyrase mutations found in Mycobacterium leprae clinical strains involved in resistance to fluoroquinolones? Antimicrob. Agents Chemother. 2008, 52, 745-747. [CrossRef] [PubMed] 
30. Sánchez-Romero, M.A.; Casadesús, J. Contribution of phenotypic heterogeneity to adaptive antibiotic resistance. Proc. Natl. Acad. Sci. USA 2014, 111, 355-360. [CrossRef] [PubMed]

31. Yoshida, H.; Bogaki, M.; Nakamura, M.; Nakamura, S. Quinolone resistance-determining region in the DNA gyrase gyrA gene of Escherichia coli. Antimicrob. Agents Chemother. 1990, 34, 1271-1272. [CrossRef] [PubMed]

32. Oppegard, L.M.; Streck, K.R.; Rosen, J.D.; Schwanz, H.A.; Drlica, K.; Kerns, R.J.; Hiasa, H. Comparison of in vitro activities of fluoroquinolone-like 2, 4- and 1, 3-diones. Antimicrob. Agents Chemother. 2010, 54, 3011-3014. [CrossRef] [PubMed]

33. Lluque, A.; Riveros, M.; Prada, A.; Ochoa, T.J.; Ruiz, J. Virulence and antimicrobial resistance in Campylobacter spp. from a Peruvian pediatric cohort. Scientifica 2017, 2017, 7848926. [CrossRef]

34. Pons, M.J.; Silva-Caso, W.; del Valle-Mendoza, J.; Ruiz, J. Multi-locus sequence typing of Bartonella bacilliformis DNA performed directly from blood of patients with Oroya's fever during a Peruvian outbreak. PLoS Negl. Trop. Dis. 2016, 10, e0004391. [CrossRef] [PubMed]

35. Gomes, C.; Martinez-Puchol, S.; Pons, M.J.; Bazán, J.; Tinco, C.; del Valle, J.; Ruiz, J. Evaluation of PCR approaches for detection of Bartonella bacilliformis in blood samples. PLoS Negl. Trop. Dis. 2016, 10, e0004529. [CrossRef] [PubMed]

36. Smit, P.W.; Peeling, R.W.; Garcia, P.J.; Torres, L.L.; Pérez-Lu, J.E.; Moore, D.; Mabey, D. Dried blood spots for qPCR diagnosis of acute Bartonella bacilliformis infection. Am. J. Trop. Med. Hyg. 2013, 89, 988-990. [CrossRef] [PubMed]

37. Flores, A.L.E. Estudios Moleculares en Bartonella bacilliformis Para el Control de la Enfermedad de Carrión. Master's Thesis, Universidad Nacional Mayor de San Marcos, Lima, Peru, 2008.

38. Espinoza-Culupú, A. Caracterización de las Regiones Determinantes de Resistencia a Antimicrobianos de Cepas de Bartonella bacilliformis de Zonas Endémicas del Perú. Master's Thesis, Universidad Nacional Mayor de San Marcos, Lima, Peru, 2014.

39. Hall, T.A. BioEdit: A user-friendly biological sequence alignment editor and analysis program for Windows 95/98/NT. Nucleic Acids Symp. Ser. 1999, 41, 95-98.

40. Tamura, K.; Peterson, D.; Peterson, N.; Stecher, G.; Nei, M.; Kumar, S. MEGA5: Molecular evolutionary genetics analysis using maximum likelihood, evolutionary distance, and maximum parsimony methods. Mol. Biol. Evol. 2011, 28, 2731-2739. [CrossRef] [PubMed] 